\title{
The Impact of Four Different Classes of Anesthetics on the Mechanisms of Blood Pressure Regulation in Normotensive and Spontaneously Hypertensive Rats
}

\author{
M. BENCZE ${ }^{1,2^{*}}$, M. BEHULIAK ${ }^{1 *}$, J. ZICHA ${ }^{1}$ \\ ${ }^{*}$ Both authors contributed to the same extent. \\ ${ }^{1}$ Institute of Physiology, Academy of Sciences of the Czech Republic, Prague, Czech Republic, \\ ${ }^{2}$ Department of Physiology, Faculty of Sciences, Charles University, Prague, Czech Republic
}

Received August 12, 2013

Accepted September 1, 2013

On-line September 10, 2013

\begin{abstract}
Summary
Most anesthetics induce characteristic hemodynamic changes leading to blood pressure (BP) reduction but the role of reninangiotensin system (RAS), sympathetic nervous system (SNS) and nitric oxide (NO) synthesis in this BP reduction is unknown. We therefore studied the influence of four widely used anesthetics - pentobarbital (P), isoflurane (ISO), ketaminexylazine $(K X)$ and chloralose-urethane $(\mathrm{CU})$ - on the participation of these vasoactive systems in BP maintenance. BP effects elicited by the acute sequential blockade of RAS (captopril), SNS (pentolinium) and NO synthase (L-NAME) were compared in conscious and anesthetized Wistar or spontaneously hypertensive rats (SHR). Except for pentobarbital all studied anesthetics evidenced by diminished BP responses to pentolinium. The absolute pentolinium-induced BP changes were always greater in SHR than Wistar rats. KX anesthesia eliminated BP response to pentolinium and considerably enhanced BP response to NO synthase inhibition in SHR. In both rat strains the anesthesia with ISO or CU augmented BP response to captopril, decreased BP response to pentolinium and attenuated $\mathrm{BP}$ response to NO synthase inhibition. In conclusion, pentobarbital anesthesia had a modest influence on BP level and its maintenance by the above vasoactive systems. Isoflurane and chloralose-urethane anesthesia may be used in cardiovascular experiments if substantial BP decrease due to altered contribution of RAS, SNS and NO to BP regulation does not interfere with the respective research aim. Major BP reduction (namely in SHR) due to a complete SNS absence is a major drawback of ketamine-xylazine anesthesia.
\end{abstract}

\section{Key words}

Sympathetic nervous system • Renin-angiotensin system • Nitric oxide • Conscious rats • Pentobarbital • Isoflurane • Ketaminexylazine $\bullet$ Chloralose-urethane

\section{Corresponding author}

J. Zicha, Institute of Physiology, Academy of Sciences of the Czech Republic, Vídeňská 1083, CZ-142 20 Prague 4, Czech Republic. Fax: +420 24106 2488. E-mail: zicha@biomed.cas.cz

\section{Introduction}

Most anesthetics cause distinct cardiovascular changes (Flecknell 2009) which include blood pressure (BP) decrease and alterations of heart rate (HR), cardiac output or stroke volume (Vidt et al. 1959, Salgado and Krieger 1976, Walker et al. 1983, Wixson et al. 1987, Janssen et al. 2004). Although almost all anesthetics lower BP in the rat, the hemodynamic mechanisms are dependent on the type of anesthetics used. Thus, ether anesthesia increases cardiac output and decreases systemic vascular resistance, while chloralose-urethane anesthesia lowers cardiac output without significant changes in systemic vascular resistance (Salgado and Krieger 1976, Smith and Hutchins 1980). The hemodynamic response to anesthesia might also differ in hypertensive animals, e.g. in spontaneously hypertensive rats (SHR) (Hall et al. 1976). Thus, pentobarbital or isoflurane anesthesia lowers cardiac output and decreases systemic vascular resistance in normotensive rats, 
whereas in SHR BP reduction is due to cardiac output reduction (Smith and Hutchins 1980, Seyde et al. 1987).

Much less attention has been paid to the influence of various anesthetics on the contribution of principal vasoactive systems to BP maintenance (Miller et al. 1983, Aisaka et al. 1991, Wang et al. 1991). Central nervous effects of most anesthetics suggest attenuation of sympathetic tone. Therefore we studied the impact of four commonly used anesthetics (pentobarbital, isoflurane, ketamine-xylazine or chloralose-urethane) on BP and HR of normotensive Wistar rats. We compared the participation of renin-angiotensin system (RAS), sympathetic nervous system (SNS) and nitric oxide (NO) in BP control of conscious and anesthetized rats. We also evaluated if these four types of anesthesia have a different influence on vasoactive system participation in SHR, since the contribution of the above vasoactive systems to BP maintenance is different in conscious normotensive and hypertensive animals (Zicha et al. 2001, Paulis et al. 2007, Behuliak et al. 2011). On the basis of information obtained we can consider which type of anesthesia would be appropriate for particular cardiovascular studies that cannot be performed in conscious animals.

\section{Materials and Methods}

Animals

The experiments were carried out in 20-weekold male Wistar rats and SHR ( $\mathrm{n}=50$ in each strain). All animals had a free access to water and ST1 rat chow (containing $1 \% \mathrm{NaCl}$ ) and were housed under standard laboratory conditions $\left(23 \pm 1^{\circ} \mathrm{C} ; 12 \mathrm{~h}\right.$ light-dark cycle). Procedures and experimental protocols, which were approved by the Ethical Committee of the Institute of Physiology AS CR, conform to European Convention on Animal Protection and Guidelines on Research Animal Use.

\section{Blood pressure measurement}

The animals were cannulated under isoflurane anesthesia 24 hours prior to the experiments on conscious rats. On the other hand, the effects of particular anesthesia ( $\mathrm{P}, \mathrm{KX}$, ISO or $\mathrm{CU})$ were studied in animals that were cannulated under the respective anesthesia just before the experiment. Carotid artery was cannulated with polyethylene catheter (PE 50) and connected to the measuring device consisting of MLT0380/D pressure transducers wired for QUAD Bridge and PowerLab/8SP (ADInstruments Ltd, Bella Vista, NSW, Australia).
Jugular vein was cannulated with polyethylene catheter (PE 10) for the application of drugs. Catheters filled with heparin were tunneled under the skin and exteriorized in the interscapular region. All experiments were performed between 8:00 AM and 11:30 AM to reduce circadian BP variations.

\section{Anesthetics}

Doses of anesthetics were chosen according to Flecknell (2009). Pentobarbital (60 mg.kg ${ }^{-1}$, Sigma, St. Louis, USA) was injected intraperitoneally. A combination of ketamine (75 mg. $\mathrm{kg}^{-1}$, Narketan, Vétoquinol, Nymburk, Czech Republic) and xylazine (5 mg.kg-1 , Rometar, Spofa, Prague, Czech Republic) was injected intramuscularly. A combination of urethane (500 mg.kg ${ }^{-1}$, Sigma) and chloralose (100 mg. $\mathrm{kg}^{-1}$, Sigma) was injected intraperitoneally. Isoflurane (Forane, Abbott, Queensborough, UK) was administered through a vaporizer ( $2 \%$ in air). Anesthetized rats were kept under heating lamp and their body temperature was continually checked to avoid body temperature variations exceeding $\pm 0.5^{\circ} \mathrm{C}$.

The sequential blockade of RAS, SNS and NO synthase (NOS)

Initial BP values were recorded just after BP stabilization. A sequential cumulative blockade of the principal vasoactive systems was performed according to a protocol of Minami et al. (1995) as described in details (Pintérová et al. 2010, Zicha et al. 2011, 2012). Initially, intravenous bolus of angiotensin-converting enzyme inhibitor captopril $\left(10 \mathrm{mg} \cdot \mathrm{kg}^{-1}\right)$ was injected to block RAS. Fifteen minutes later, SNS was inhibited by ganglionic blocker pentolinium $\left(5 \mathrm{mg} \cdot \mathrm{kg}^{-1}\right)$. After BP stabilization for $5 \mathrm{~min}$, NOS inhibitor $\mathrm{N}^{\mathrm{G}}$-nitro-Larginine methyl ester (L-NAME, $30 \mathrm{mg} \cdot \mathrm{kg}^{-1}$ ) was given and BP was monitored for $20 \mathrm{~min}$ (Fig. 1). All drugs purchased from Sigma were dissolved in saline $(0.9 \%$ $\mathrm{NaCl}$ ) and given as an intravenous bolus in a volume of $1 \mathrm{ml} . \mathrm{kg}^{-1}$ body weight. The used drug doses elicited maximal BP effects (Zicha et al. 2006). Vasoactive system participation in BP maintenance was evaluated on the basis of BP changes, which were elicited by the sequential blockade of particular vasoconstrictor and vasodilator systems. Our experimental protocol used in this study was designed to minimize the compensatory interactions between vasoactive systems in conscious rats, in which the reversed sequence of SNS and RAS blockade (pentolinium injection followed by captopril 
administration) yielded similar BP effects as the used sequence (captopril followed by pentolinium (Table 1). Nevertheless, in this study we have also evaluated direct BP effects of SNS blockade by pentolinium (applied without previous RAS blockade by captopril) in conscious rats and in rats anesthetized with pentobarbital, isoflurane or chloralose-urethane.
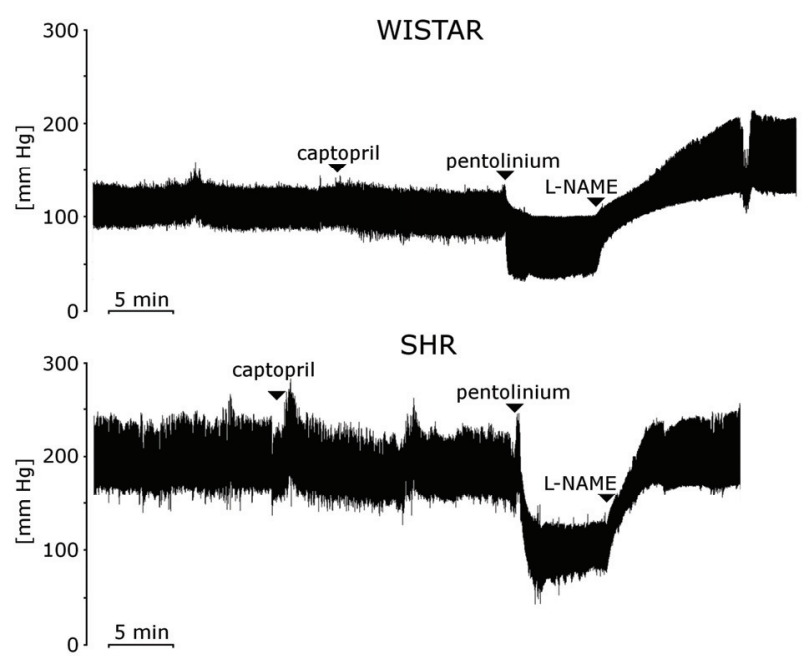

Fig. 1. Representative authentic recordings of blood pressure changes in conscious Wistar rats and spontaneously hypertensive rats (SHR) during the sequential blockade of RAS by captopril $\left(10 \mathrm{mg} \cdot \mathrm{kg}^{-1}\right)$, SNS by pentolinium $\left(5 \mathrm{mg} \cdot \mathrm{kg}^{-1}\right)$ and NOS by L-NAME $\left(30 \mathrm{mg}^{\circ} \mathrm{kg}^{-1}\right)$.

Table 1. Mean arterial pressure (MAP) and its response to RAS and SNS blockade (in both sequences of inhibitor administration) and to NO synthase blockade in conscious normotensive Wistar rats and spontaneously hypertensive rats (SHR).

\begin{tabular}{lcc}
\hline & Wistar & SHR \\
\hline \multicolumn{3}{c}{ Captopril followed by Pentolinium } \\
Basal MAP & $112 \pm 3$ & $191 \pm 3^{*}$ \\
Delta MAP captopril & $-12 \pm 2$ & $-9 \pm 5$ \\
Delta MAP pentolinium & $-47 \pm 2$ & $-87 \pm 5^{*}$ \\
Delta MAP L-NAME & $101 \pm 2$ & $99 \pm 4$ \\
Final MAP & $154 \pm 4$ & $194 \pm 3^{*}$ \\
Pentolinium followed by Captopril & \\
Basal MAP & $121 \pm 2$ & $181 \pm 3^{*}$ \\
Delta MAP pentolinium & $-47 \pm 2$ & $-85 \pm 6^{*}$ \\
Delta MAP captopril & $-16 \pm 2$ & $-16 \pm 1$ \\
Delta MAP L-NAME & $73 \pm 7$ & $92 \pm 3$ \\
Final MAP & $132 \pm 6$ & $180 \pm 2^{*}$ \\
\hline
\end{tabular}

Data are means \pm SEM (4-6 animals per group). $* \mathrm{P}<0.05$ as compared to Wistar rats.
Statistical analysis

The data were expressed as mean \pm SEM. The effects of the drugs were analyzed as absolute BP changes in $\mathrm{mm} \mathrm{Hg}$ as well as relative BP changes in percentage of baseline BP. The same approach was used for the evaluation of HR changes. ANOVA with post-hoc Bonferroni test were used for the multiple group comparison. The data were considered significant at $\mathrm{P}<0.05$ level.

\section{Results}

BP effects of particular anesthetics in Wistar and SHR animals

Baseline mean arterial pressure (MAP) of conscious Wistar rats was $112 \pm 3 \mathrm{~mm} \mathrm{Hg}$ and it did not change significantly under pentobarbital anesthesia, but it was moderately lowered during ISO or CU anesthesia (Fig. 2A). Baseline HR in all anesthetized groups did not differ significantly from the values in conscious rats (Fig. 2B).
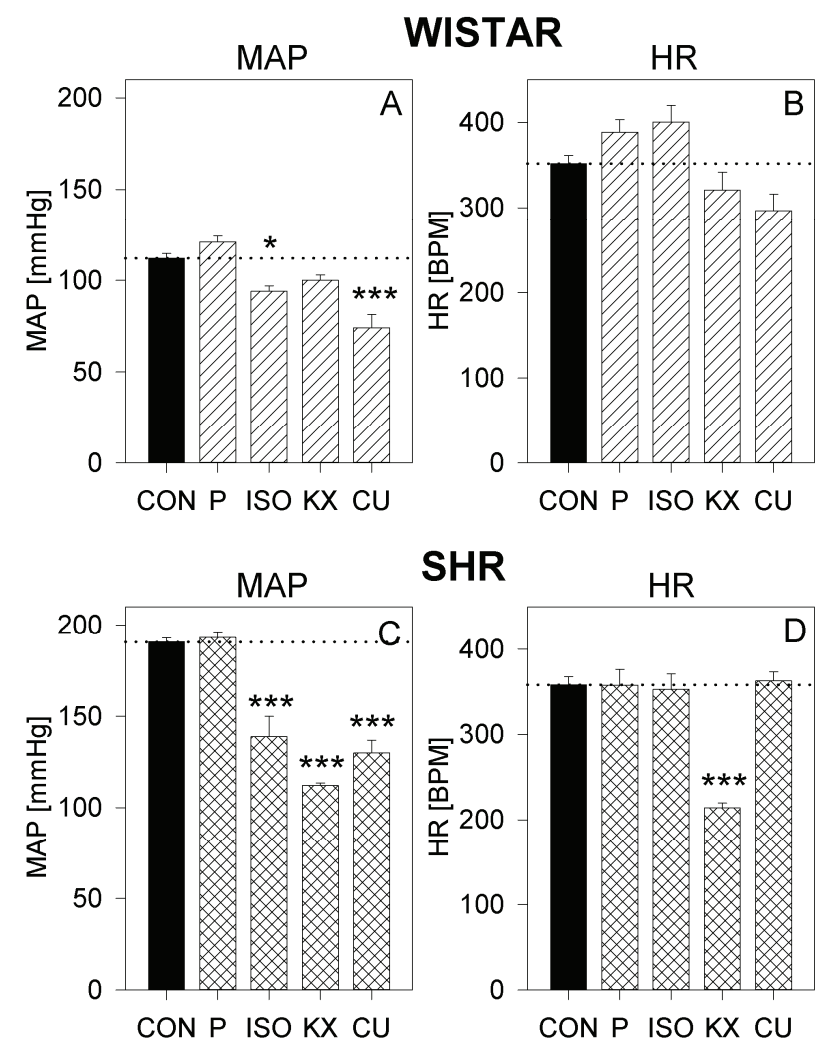

Fig. 2. Mean arterial pressure (MAP) and heart rate (HR) in conscious rats (CON) as well as in Wistar and SHR animals anesthetized with pentobarbital (P), isoflurane (ISO), ketaminexylazine $(\mathrm{KX})$ or chloralose-urethane (CU). Data are means \pm SEM, $n=6$ per group. ANOVA $F_{4,27}=20.31(P<0.001), 5.53$ $(P<0.002), 45.60(P<0.001)$ and $23.68(P<0.001)$ for panels A-D. $* \mathrm{P}<0.05 ;{ }^{* *} \mathrm{P}<0.01 ; * * * \mathrm{P}<0.001$ as compared to conscious rats (Bonferroni post-hoc test). 

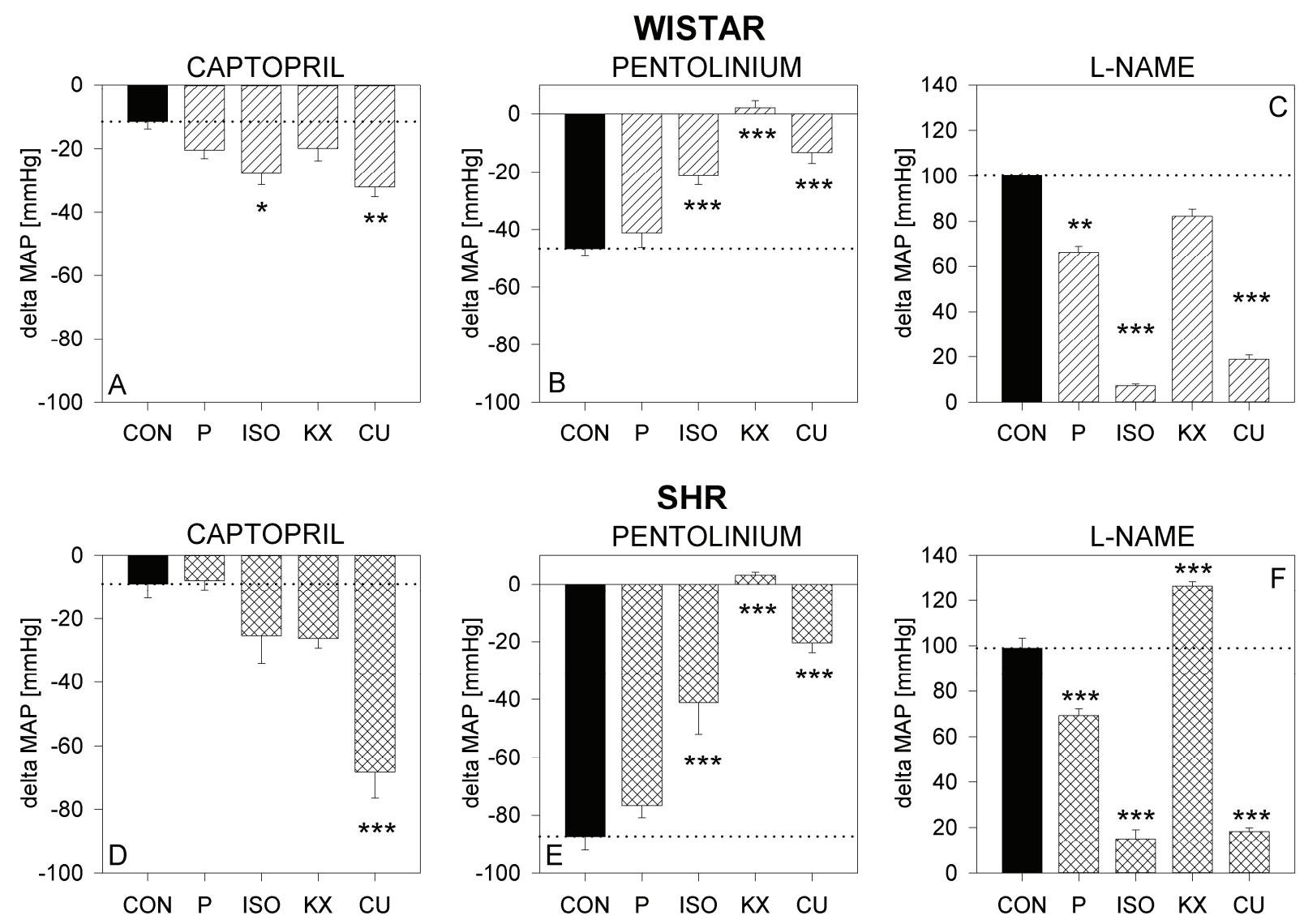

Fig. 3. MAP responses to RAS blockade by captopril, to SNS blockade by pentolinium and NOS blockade by L-NAME in conscious and anesthetized Wistar and SHR animals. For abbreviations and other legend see Figure 2. ANOVA $F_{4,27}=4.54(P=0.006), 30.28(P<0.001)$, $35.01(\mathrm{P}<0.001), 16.99(\mathrm{P}<0.001), 48.03(\mathrm{P}<0.001)$ and $222.55(\mathrm{P}<0.001)$ for panels A-F. $* \mathrm{P}<0.05 ; * * \mathrm{P}<0.01 ; * * * \mathrm{P}<0.001$ as compared to conscious rats (Bonferroni post-hoc test).

MAP of conscious SHR $(191 \pm 3 \mathrm{~mm} \mathrm{Hg})$ was elevated compared to conscious Wistar rats and this difference was preserved under all forms of anesthesia used (Fig. 2C). The magnitude of absolute MAP changes induced by particular types of anesthesia was greater in SHR than in Wistar rats (Fig. 2). However, the relative MAP changes (in percentage of baseline MAP of conscious rats) were similar in both strain except of those induced by $\mathrm{KX}$ anesthesia which were still greater in SHR than in Wistar rats $(-41 \pm 1$ vs. $-11 \pm 3 \%, \mathrm{p}<0.001)$. KX was the only anesthetic which lowered HR of SHR as compared to conscious SHR (Fig. 2D).

The contribution of RAS, SNS and NO to BP maintenance in anesthetized Wistar rats

The small captopril-induced MAP changes in conscious Wistar rats were significantly augmented under ISO or CU anesthesia (Fig. 3A), indicating enhanced contribution of RAS to BP maintenance in these anesthetized animals. The same was also true for the relative captopril-induced MAP changes (conscious
$-10 \pm 2 \%$ vs. ISO $-29 \pm 3$ and CU $-43 \pm 2 \%$ of baseline MAP). The relative pentolinium-induced MAP changes in P-anesthetized rats $(-40 \pm 2 \%)$ were similar as in conscious rats $(-46 \pm 3 \%)$, suggesting unaltered contribution of SNS to BP maintenance under pentobarbital anesthesia. Under ISO or CU anesthesia the participation of SNS was significantly attenuated, whereas KX anesthesia completely abolished SNS participation in BP maintenance (Fig. 3B). MAP response to NOS inhibition was attenuated in all anesthetized groups as compared with conscious animals. However, L-NAME-induced MAP changes were moderately attenuated under $\mathrm{P}$ and $\mathrm{KX}$ anesthesia but severely suppressed under ISO and CU anesthesia (Fig. 3C).

The contribution of RAS, SNS and NO to BP maintenance in anesthetized SHR

MAP changes elicited in SHR by the blockade of particular vasoconstrictor and vasodilator systems were qualitatively similar as those observed in normotensive Wistar rats measured under the same 
Table 2. Mean arterial pressure (MAP) response to SNS blockade (without previous RAS blockade) in conscious and anesthetized normotensive Wistar rats and spontaneously hypertensive rats (SHR).

\begin{tabular}{lccccc}
\hline & Conscious & Pentobarbital & Isoflurane & Chloralose-urethane & F $_{\mathbf{3}, \mathbf{1}}$ ratio \\
\hline $\begin{array}{l}\text { Wistar } n= \\
\text { Basal MAP }\end{array}$ & 6 & 5 & 6 & 6 & \\
& $121 \pm 2$ & $119 \pm 9$ & $93 \pm 6^{*}$ & $62 \pm 3^{*}$ & 27.3 \\
Delta MAP pentolinium & $-47 \pm 2$ & $-53 \pm 9$ & $-36 \pm 5$ & $-17 \pm 5^{*}$ & $\begin{array}{c}\mathrm{P}<0.0001 \\
\\
\end{array}$ \\
SHR $n=$ & 6 & & & 8.4 \\
Basal MAP & $181 \pm 3$ & $187 \pm 4$ & $134 \pm 2^{*}$ & $123 \pm 9^{*}$ & \\
Delta MAP pentolinium & $-85 \pm 6$ & $-94 \pm 5$ & $-54 \pm 2^{*}$ & $-64 \pm 8^{*}$ & 45.3 \\
& & & & & $\mathrm{P}<0.0001$ \\
& & & & 11.8 \\
& & & & $\mathrm{P}<0.001$ \\
\hline
\end{tabular}

Data are means \pm SEM. Significantly different $(\mathrm{P}<0.05): *$ vs. conscious rats.

conditions (Fig. 3). The most striking quantitative strain difference was the augmented magnitude of absolute pentolinium-induced MAP responses in SHR groups which was proportional to the elevation of their basal MAP (Figs 3B vs. 3E). Nevertheless, no significant differences in the relative contribution of SNS to BP maintenance were found between SHR and Wistar rats. A greater absolute captopril-induced MAP changes were found in CU-anesthetized SHR compared to Wistar rats (Fig. 3A vs. 3D). The absolute L-NAME-induced MAP changes in most groups of SHR were similar to those found in Wistar rats (Figs 3C vs. 3F) but an abnormally high BP response to L-NAME was observed in KX-anesthetized SHR.

Table 2 shows that both isoflurane and chloralose-urethane anesthesia diminished SNSdependent BP component even if pentolinium was administered without preceding RAS blockade by captopril. This is evident in both SHR and Wistar rats. On the other hand, pentobarbital anesthesia did not modify significantly the contribution of SNS to BP maintenance (Table 2).

\section{Discussion}

Our comparison of conscious rats with animals subjected to four different widely used anesthetics revealed numerous changes in $\mathrm{BP}$ level as well as in the involvement of major vasoactive systems in BP maintenance, which were often dependent on the type of anesthesia used (Table 3). All anesthetics except for pentobarbital lowered BP in normotensive and hypertensive rats due to the attenuation of SNS contribution to BP maintenance. The absolute (but not the relative) pentolinium-induced $\mathrm{BP}$ changes were more pronounced in SHR, which are characterized by enhanced SNS activity (Head 1989, Pintérová et al. 2011). No significant BP response to ganglionic blockade by pentolinium was observed in KX-anesthetized rats of both strains because the central effects of $\alpha_{2}$-adrenoceptor agonist xylazine (Hsu 1981, Guimarães and Moura 2001) completely abolished sympathetic outflow in animals subjected to this type of anesthesia. In addition, a pronounced BP reduction in $\mathrm{KX}$-anesthetized SHR (Fig. 2D) can also be partially attributed to a major reduction of HR and cardiac output (Saha et al. 2007).

Table 3. The influence of different anesthetics on mean arterial pressure (MAP) and on the role of principle vasoactive systems (renin-angiotensin system - RAS, sympathetic nervous system SNS and nitric oxide - NO) in BP maintenance of Wistar/SHR animals.

\begin{tabular}{lcccc} 
Anesthetic & MAP & RAS & SNS & NO \\
\hline Pentobarbital & $=/=$ & $=/=$ & $=/=$ & $\downarrow / \downarrow$ \\
Isoflurane & $\downarrow / \downarrow$ & $\uparrow / \uparrow$ & $\downarrow / \downarrow$ & $\downarrow / \downarrow$ \\
Ketamine-xylazine & $\downarrow / \downarrow$ & $=/ \uparrow$ & $\downarrow / \downarrow$ & $\downarrow / \uparrow$ \\
Chloralose-urethane & $\downarrow / \downarrow$ & $\uparrow / \uparrow$ & $\downarrow / \downarrow$ & $\downarrow / \downarrow$ \\
\hline
\end{tabular}

Pentobarbital anesthesia seems to cause smaller hemodynamic changes than the other anesthetics because 
basal BP as well as BP responses to the SNS and RAS blockade were not altered as compared to conscious animals. A decreased BP response to NOS inhibition pointed to the only vasoactive system by which our pentobarbital-anesthetized rats differed from conscious animals. This difference may be caused by anesthesiainduced alterations of NO synthesis and/or NO release (Toda et al. 2007). Nevertheless, ganglionic blockade by pentolinium caused a similar BP reduction but a considerably greater HR reduction in $\mathrm{P}$-anesthetized rats as compared to conscious animals of both strains (Fig. 4). Therefore we assume that a decrease in HR and cardiac output was compensated by the rise of systemic resistance due to the attenuation of NO-dependent vasodilatation and/or due to the enhancement of remaining vasoconstrictor systems such as endothelin, vasopressin etc. Pentolinium-induced HR reduction in rats anesthetized with $\mathrm{P}$, ISO or CU (Fig. 4) represents an important hemodynamic difference compared to conscious animals in which ganglionic blockade caused only a non-significant HR changes. These effects of the above mentioned anesthetics were significant only in SHR but not in Wistar rats (Fig. 4).
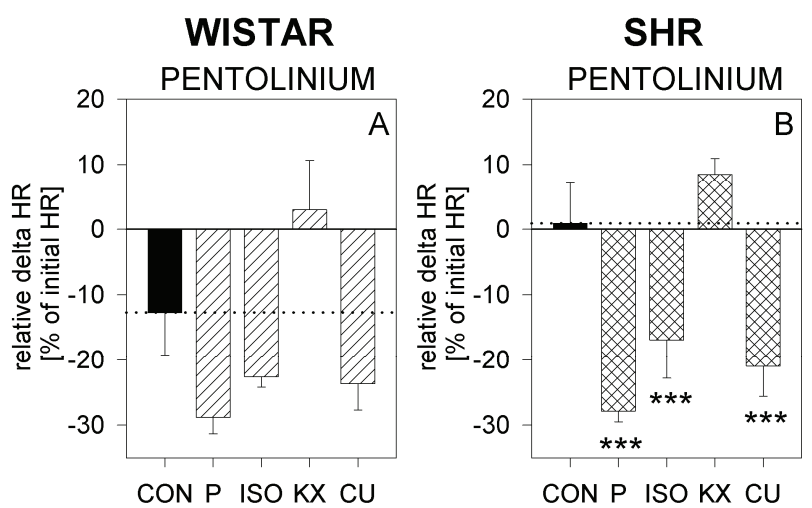

Fig. 4. Relative HR changes after SNS blockade by pentolinium in conscious (CON) Wistar and SHR animals and in rats anesthetized with pentobarbital (P), isoflurane (ISO), ketaminexylazine (KX) or chloralose-urethane (CU). Relative changes are expressed in percentage of baseline MAP values. Data are means $\pm \mathrm{SEM}, \mathrm{n}=6$ per group. ANOVA $\mathrm{F}_{4,27}=6.43(\mathrm{P}<0.001)$ and 12.31 $(\mathrm{P}<0.001)$ for panels $\mathbf{A}$ and $\mathbf{B} .{ }^{* * * P}<0.001$ as compared to conscious rats (Bonferroni post-hoc test).

The anesthetics used in our study influenced the involvement of RAS in BP regulating mechanisms similarly in hypertensive and normotensive rats. There was usually a mild enhancement of RAS contribution to BP maintenance in anesthetized rats as it was reported by Miller et al. (1983). However, under CU anesthesia the acute RAS blockade by captopril caused a more pronounced BP fall in SHR than in Wistar rats. It is possible that this anesthesia may potentiate the importance of RAS more in SHR than in Wistar rats.

The anesthesia with ISO or CU lowered BP due to a considerable reduction of SNS contribution to $\mathrm{BP}$ maintenance, whereas RAS contribution was slightly augmented. This was accompanied by a pronounced attenuation of BP response to NOS inhibition in both rat strains. In both ISO- and CU-anesthetized rats there is a major reduction of residual MAP (recorded after a combined RAS and SNS blockade), indicating a profound relaxation of resistance vessels. Such a relaxation is present in both Wistar and SHR, but the difference in residual MAP between these normotensive and hypertensive rats is still preserved. This observation suggests a considerable attenuation of vascular tone due to the action of these two anesthetics at the level of vascular smooth muscle. We have made a similar observation in SHR pretreated with pertussis toxin to inactivate inhibitory $G$ proteins and $\alpha_{2}$-adrenoceptormediated signal transmission (Pintérová et al. 2010). This intervention caused BP reduction, attenuation of SNS contribution and enhancement of RAS contribution to BP maintenance.

Although there is a scarce information about chloralose-urethane effects on vascular smooth muscle, several studies (Yamazaki et al. 1998, Stekiel et al. 1999, Stekiel et al. 2001) indicated that isoflurane caused a hyperpolarization of vascular smooth muscle in resistance vessels leading to a decreased vascular tone. This ISOinduced hyperpolarization of vascular smooth muscle has two distinct components. A more important mechanism is the central neural inhibition of excitatory sympathetic output which is augmented in SHR; the additional component is based upon a peripheral neurally and nonneurally mediated hyperpolarization of vascular smooth muscle that is similar in both rat strains (Stekiel et al. 1999). The mechanisms of the latter hyperpolarization component are the activation of $\mathrm{K}_{\mathrm{Ca}}$ and $\mathrm{K}_{\mathrm{ATP}}$ channels (Stekiel et al. 2001) and the inhibition of $\mathrm{Ca}^{2+}$ influx through voltage-gated $\mathrm{Ca}^{2+}$ channels (Akata et al. 2007). This is compatible with our observation of reduced MAP response to NOS inhibition in ISO-anesthetized rats. The augmentation of cAMP formation by volatile anesthetics not only enhances the activity of $\mathrm{K}^{+}$channels but also attenuates vascular contraction elicited by the lack of cGMP following the inhibition of NO synthase and/or soluble guanylate cyclase (Stekiel et al. 2001). 
The detailed hemodynamic comparison of conscious and CU-anesthetized rats (Faber 1989) indicated the reduction of basal BP, decreased BP response to ganglionic blockade, enhanced $\mathrm{BP}$ response to peripheral angiotensin II receptor blockade and the attenuation of BP response to dose-dependent intravenous administration of either $\alpha_{1}$-adrenoceptor agonist phenylephrine or NO donor nitroglycerin in the anesthetized animals. This is in line with our findings that suggested the attenuation of SNS contribution but the enhancement of RAS contribution to BP maintenance in CU-anesthetized rats which are characterized by a profound reduction of residual MAP due to enhanced vasorelaxation.

In conclusions, the anesthesia should be selected according to its cardiovascular effects in order to prevent the undesirable interference with the goals of experimental protocol scheduled. Our results indicate that the interference of pentobarbital anesthesia with cardiovascular experiments is smaller as compared to other anesthetics used in our study. Isoflurane and chloralose-urethane anesthesia can be used in cardiovascular experiments if lowered BP, enhanced contribution of RAS and/or decreased contribution of SNS and NO to BP regulation are not considered to interfere with the studied cardiovascular parameter(s). Moreover, the use of isoflurane anesthesia is complicated by its activation of $\mathrm{K}^{+}$channels and resulting membrane hyperpolarization which might modify numerous functional studies of the cardiovascular system. On the other hand, ketamine-xylazine anesthesia is not appropriate for performing functional cardiovascular studies.

\section{Conflict of Interest}

There is no conflict of interest.

\section{Acknowledgements}

Valuable comments of Dr. Ivana Vaněčková and Dr. Jaroslav Kuneš are highly appreciated. This work was supported by grants AV0Z 50110509, GACR 304/12/0259 (Czech Science Foundation) and GAUK 7922/2013 (Grant Agency of Charles University).

\section{References}

AISAKA K, MITANI A, KITAJIMA Y, OHNO T, ISHIHARA T: Difference in pressor responses to N ${ }^{\mathrm{G}}$-monomethylL-arginine between conscious and anesthetized rats. Jpn J Pharmacol 56: 245-248, 1991.

AKATA T, KANNA T, YOSHINO J, TAKAHASHI S: Mechanisms of direct inhibitory action of isoflurane on vascular smooth muscle of mesenteric resistance arteries. Anesthesiology 99: 666-677, 2003.

BEHULIAK M, PINTÉROVÁ M, KUNEŠ J, ZICHA J: Vasodilator efficiency of endogenous prostanoids, $\mathrm{Ca}^{2+}$-activated $\mathrm{K}^{+}$channels and nitric oxide in rats with spontaneous, salt-dependent or NO-deficient hypertension. Hypertens Res 34: 968-975, 2011.

FABER JE: Effects of althesin and urethan-chloralose on neurohumoral cardiovascular regulation. Am J Physiol Regul Integr Comp Physiol 256: R757-R765, 1989.

FLECKNELL P: Laboratory Animal Anaesthesia. Academic Press, San Diego, 2009.

GUIMARÃES S, MOURA D: Vascular adrenoceptors: an update. Pharmacol Rev 53: 319-356, 2001.

HALL CE, AYACHI S, HALL O: Differential sensitivity of spontaneously hypertensive rats (SHR) and control rats to various anesthetic agents. Clin Exp Pharmacol Physiol 4 (Suppl 3): 83-86, 1976.

HEAD RJ: Hypernoradrenergic innervation: its relationship to functional and hyperplastic changes in the vasculature of the spontaneously hypertensive rat. Blood Vessels 26: 1-20, 1989.

HSU WH: Xylazine-induced depression and its antagonism by alpha adrenergic blocking agents. J Pharmacol Exp Ther 218: 188-192, 1981.

JANSSEN BJ, DE CELLE T, DEBETS JJ, BROUNS AE, CALLAHAN MF, SMITH TL: Effects of anesthetics on systemic hemodynamics in mice. Am J Physiol Heart Circ Physiol 287: H1618-H1624, 2004.

MILLER ED JR, BECKMAN JJ, WOODSIDE JR JR, ALTHAUS MS, PEACH MJ: Blood pressure control during anesthesia: importance of the peripheral sympathetic nervous system and renin. Anesthesiology 58: 32-37, 1983. 
MINAMI N, IMAI Y, HASHIMOTO J, ABE K: Contribution of vascular nitric oxide to basal blood pressure in conscious spontaneously hypertensive rats and normotensive Wistar Kyoto rats. Clin Sci (Lond) 89: 177-182, 1995.

PAULIS L, LÍŠKOVÁ S, PINTÉROVÁ M, DOBEŠOVÁ Z, KUNEŠ J, ZICHA J: Nifedipine-sensitive noradrenergic vasoconstriction is enhanced in spontaneously hypertensive rats: the influence of chronic captopril treatment. Acta Physiol (Oxford) 191: 255-266, 2007.

PINTÉROVÁ M, KAREN P, KUNEŠ J, ZICHA J: Role of nifedipine-sensitive sympathetic vasoconstriction in maintenance of high blood pressure in spontaneously hypertensive rats: effect of $\mathrm{G}_{\mathrm{i}}$-protein inactivation by pertussis toxin. $J$ Hypertens 28: 969-978, 2010.

PINTÉROVÁ M, KUNEŠ J, ZICHA J: Altered neural and vascular mechanisms in hypertension. Physiol Res 60: 381-402, 2011.

SAHA DC, SAHA AC, MALIK G, ASTIZ ME, RACKOW EC: Comparison of cardiovascular effects of tiletaminezolazepam, pentobarbital, and ketamine-xylazine in male rats. J Am Assoc Lab Anim Sci 46: 74-80, 2007.

SALGADO MCO, KRIEGER EM: Cardiac output in unrestrained rats. Clin Exp Pharmacol Physiol 4 (Suppl 3): 165-167, 1976.

SEYDE WC, DURIEUX ME, LONGNECKER DE: The hemodynamic response to isoflurane is altered in genetically hypertensive (SHR), as compared with normotensive (WKY), rats. Anesthesiology 66: 798-804, 1987.

SMITH TL, HUTCHINS PM: Anesthetic effects on hemodynamics of spontaneously hypertensive and Wistar-Kyoto rats. Am J Physiol 238: H539-H544, 1980.

STEKIEL TA, CONTNEY SJ, KOKITA N, BOSNJAK ZJ, KAMPINE JP, STEKIEL WJ: Mechanisms of isofluranemediated hyperpolarization of vascular smooth muscle in chronically hypertensive and normotensive conditions. Anesthesiology 94: 496-506, 2001.

STEKIEL TA, KOKITA N, YAMAZAKI M, BOSNJAK ZJ, KAMPINE JP, STEKIEL WJ: Effect of isoflurane on in situ vascular smooth muscle transmembrane potential in spontaneous hypertension. Anesthesiology 91: 207-214, 1999.

TODA N, TODA H, HATANO Y: Nitric oxide: involvement in the effects of anesthetic agents. Anesthesiology 107: 822-842, 2007.

VIDT DG, BREDEMEYER A, SAPIRSTEIN E, SAPIRSTEIN LA: Effect of ether anesthesia on the cardiac output, blood pressure, and distribution of blood flow in the albino rat. Circ Res 7: 759-764, 1959.

WANG YX, ZHOU T, CHUA TC, PANG CC: Effects of inhalation and intravenous anesthetic agents on pressor response to $\mathrm{N}^{\mathrm{G}}$-nitro-L-arginine. Eur J Pharmacol 198: 183-188, 1991.

WALKER LA, BUSCEMI-BERGIN M, GELLAI M: Renal hemodynamics in conscious rats: effects of anesthesia, surgery, and recovery. Am J Physiol 245: F67-F74, 1983.

WIXSON SK, WHITE WJ, HUGHES HC JR, LANG CM, MARSHALL WK: The effects of pentobarbital, fentanyldroperidol, ketamine-xylazine and ketamine-diazepam on arterial blood $\mathrm{pH}$, blood gases, mean arterial blood pressure and heart rate in adult male rats. Lab Anim Sci 37: 736-742, 1987.

YAMAZAKI M, STEKIEL TA, BOSNJAK ZJ, KAMPINE JP, STEKIEL WJ: Effects of volatile anesthetic agents on in situ vascular smooth muscle transmembrane potential in resistance- and capacitance-regulating blood vessels. Anesthesiology 88: 1085-1095, 1998.

ZICHA J, DOBEŠOVÁ Z, KUNEŠ J: Relative deficiency of nitric oxide-dependent vasodilation in salt hypertensive Dahl rats: the possible role of superoxide anions. J Hypertens 19: 247-254, 2001.

ZICHA J, DOBEŠOVÁ Z, KUNEŠ J: Antihypertensive mechanisms of chronic captopril or N-acetylcysteine treatment in L-NAME hypertensive rats. Hypertens Res 29: 1021-1027, 2006.

ZICHA J, DOBEŠOVÁ Z, BEHULIAK M, KUNEŠ J, VANĚČKOVÁ I: Preventive dietary potassium supplementation in young salt-sensitive Dahl rats attenuates development of salt hypertension by decreasing sympathetic vasoconstriction. Acta Physiol (Oxf) 202: 29-38, 2011.

ZICHA J, DOBEŠOVÁ Z, KUNEŠ J, VANĚČKOVÁ I: Chronic endothelin A receptor blockade attenuates contribution of sympathetic nervous system to salt hypertension development in adult but not in young Dahl rats. Acta Physiol (Oxf) 205: 124-132, 2012. 